\section{Uptake and Incorporation of Labelled Glycine by Pogonophores}

Members of the phylum Pogonophora are unique among free-living Metazoa in being without an internal digestive system at any stage in their life history ${ }^{1}$. Until recently very little real evidence has been obtained as to how they feed. To some extent the lack of knowledge of the physiology of the group results from the difficulty in collecting and working with predominantly deep water benthic animals ${ }^{3}$ and it has been necessary to rely on anatomical and histological data. By analogy with tube-living polychaete worms it has been suggested that the tentacle or tentacles might collect particulate food, which might then be digested and assimilated in temporary "stomachs" formed by the adjoined or rolled-up tentacles ${ }^{1}$. This theory is rendered less likely by the lack of ciliation of the tentacles of many species and by the absence of any real glandular development that might be associated with digestion ${ }^{4,5}$, and an alternative hypothesis has therefore been put forward: that pogonophores rely on direct absorption of organic matter from seawater or from the mud in which they live ${ }^{4}$. Certainly, the fine structure of the cuticle covering the tentacle and the rest of the body shows it to be well fitted for absorption or assimilation (refs. 6 and 7 and our unpublished results).

The preliminary experiments reported here form part of an investigation of the biology of the benthos of the continental slope and were designed to discover if pogonophores could take up simple organic compounds from very dilute solutions. The species selected was Siboglinum atlanticum $^{8}$, obtained in this instance from a depth of $1,600 \mathrm{~m}$ off Santander in the southern Bay of Biscay. The work was carried out on board RV Sarsia, and all animals were used within 1 or $2 \mathrm{~h}$ of capture: it is im. portant to use fresh material when working with pogonophores, for dredging usually causes some damage to the posterior end, which is rarely complete ${ }^{9,10}$. The bottom temperature in the locality is about $5^{\circ} \mathrm{C}$ and the specimens were kept at about $4^{\circ} \mathrm{C}$ throughout the work. Individuals in good condition were selected under a stereomicroscope, and the ends of the tube were clipped short to remove any mud that may have entered while dredging and to ensure access to the animal. The tubes were then rinsed in sterile seawater, and each specimen was placed in $12 \mathrm{ml}$. sterile seawater enriched with tritium-labelled glycine at a level of $10^{-6}$ or $10^{-7} \mathrm{M}$, and with a total activity of 1.6 or $0.16 \mu \mathrm{Ci} / 12 \mathrm{ml}$. After from 3-12 h of incubation the animals were fixed in cold calcium-formol, dehydrated slowly with ethanol, cleared in benzene and stored in liquid paraffin. At the laboratory the specimens were embedded in hard wax and sectioned, with some difficulty, still inside their chitinous tubes. The sections were coated with diluted Ilford $K 2$ nuclear emulsion ${ }^{11}$ and

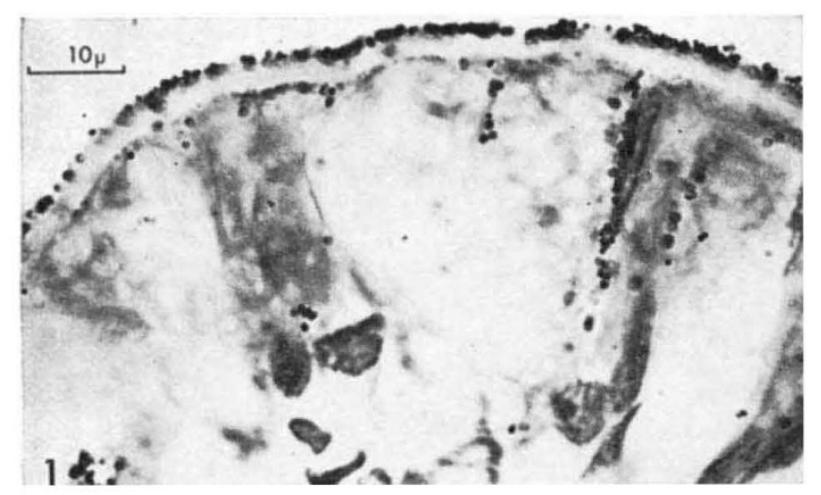

Fig. 1. Autoradiograph of part of transverse section of cephalic lobe of Siboglinum allanticum after $3 \mathrm{~h}$ exposure to $10^{-6} \mathrm{M}^{3} \mathrm{H}$-glycine, showing labelling (black spots) in the thick cuticle and the large epidermal cells below. Lightly stained with Mayer's haemalum.

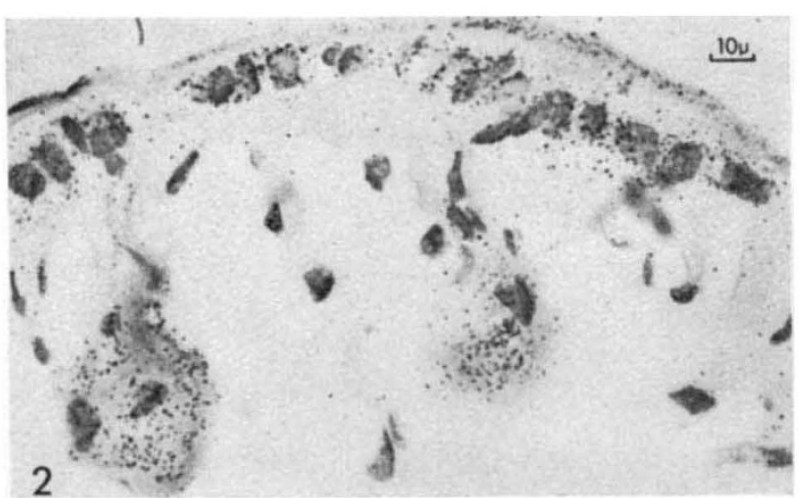

Fig. 2. Autoradjograph of part of transverse section of posterior region of forepart, after $12 \mathrm{~h}$ exposure to $10^{-6} \mathrm{M}^{3} \mathrm{H}$-glycine, showing labelling in the cuticle, the epidermal cells and in two pyriform glands.

exposed for 2 and 4 months, the resulting autoradiographs being developed in $D 19 b$ for 4-7 min.

Because conditions at sea would not allow a great variety of experiment, no attempt was made to assess the extent of free amino-acid uptake and transport. We concentrated on this one technique, which it was hoped would show whether or not uptake occurred while the animal was still in the tube and demonstrate regions of subsequent binding in the tissues. The results of the 2 and 4 months exposures show that glycine is taken up from solutions of $10^{-6}$ and $10^{-7} \mathrm{M}$. In specimens incubated for only $3-3.5 \mathrm{~h}$ the labelling appears to be confined to the anterior end of the body, especially the cuticle of the cephalic lobe (Fig. 1) and forepart, and to the epidermal cells of the same region; no signs of activity were found in the tentacle, and little or none in the metameric and postmetameric regions. At $10^{-7} \mathrm{M}$ the activity seemed almost entirely confined to the cuticle.

After $12 \mathrm{~h}$ of incubation in $10^{-6} \mathrm{M}$ glycine the labelling was present throughout the body as well as in the cuticle and epidermis of the forepart. High activity was seen in the pyriform glands of the forepart (Fig. 2) and metameric regions, which secrete large quantities of mucopolysaccharide (including the chitin that forms the tube ${ }^{5}$ ), in the yellow and white protein-containing cells, and around the ventral groove. That is, most of the labelled glycine was found either in the cuticle of the forepart and in the epidermal cells close to it, or in regions of active secretion and storage. Little activity was present, however, in the cells of the ciliated band or in the thin cuticle over them. In all specimens the nature of the cuticle labelling was very similar: the grains were most densely accumulated in an outer layer which has been identified as sulphated acid mucopolysaccharide in light microscope preparations ${ }^{5}$ and which in electron microscope preparations appears to correspond to a layer of rounded vesicles (Fig. 3). These vesicles, or membrane-bounded blebs ${ }^{7}$, are present to some extent in the tentacle, but we find them to be much more numerous on the forepart of the body and to a lesser extent in certain parts of the metameric region.

Our observations show only sites of binding of glycine, and the high activity in the peripheral areas of the forepart does not mean that uptake occurs there rather than in the tentacle. Meanwhile it is obvious that the pogonophore cuticle, particularly over the forepart and tentacle, is a very active part of the body; we have previously identified several enzymes associated with it, including esterase resistant to $\mathrm{E} 600$ and acid phosphatase ${ }^{5}$, and recently an arylamidase or exopeptidase was demonstrated. These enzymes could well be part of the mechanism of uptake.

It must be emphasized that the mere occurrence of uptake of amino-acids from concentrations of the order of those thought to be present in the sea and in the 


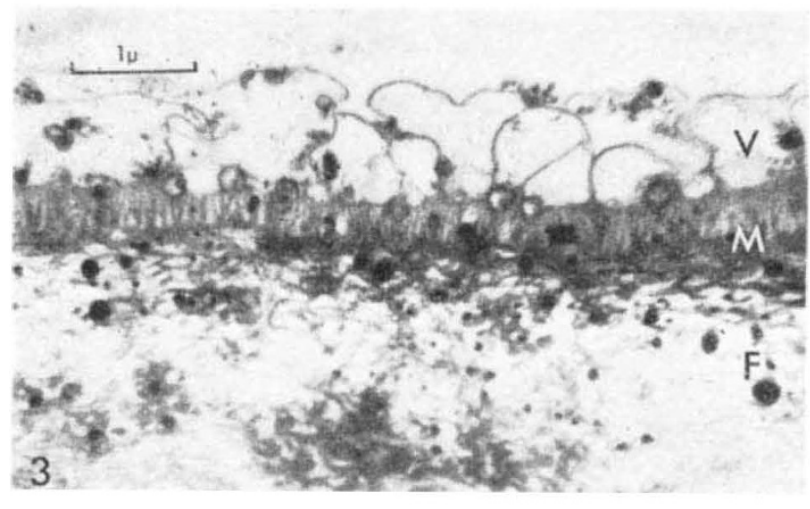

Fig. 3. Electron micrograph of vertical section of cuticle of cephalic lobe. Fixed glutaraldehyde, post-fixed osmic acid, stained lead and uranium.

surface layers of the mud ${ }^{12-14}$ is by no means proof that pogonophores can exist on such food. Many other softbodied marine invertebrates have been shown to take up amino-acids and sugars from very dilute solutions, even though they also possess internal digestive systems ${ }^{15-18}$. We have not yet been able to show any uptake of glucose, and there is the question of very large molecules to consider. Nevertheless, it is tempting to suggest that although most animals may have some capacity for direct absorption of organic matter, the pogonophores have developed this capacity to the point where a gut is not needed.

We thank many colleagues for help and advice, particularly Professor A. R. Fontaine, Dr C. Manwell and Dr D. Nicholls. We also thank Mr A. C. G. Best for the electron micrographs and Miss J. Kibble and Mrs B. Smith for technical assistance.

\section{A. J. Southward}

Eve C. Southward

Marine Biological Association,

Citadel Hill,

Plymouth.

Received April 19, 1968.

${ }^{1}$ Ivanov, A. V., Pogonophora (Academic Press, London, 1963).

${ }^{2}$ Caullery, M., Siboga Exped. Monograph, 25 (1914); ibid., 25 (1944).

${ }^{3}$ Southward, A. J., and Southward, E. C., J. Mar. Biol. Assoc. UK, 43, 57 (1963).

4 Jagersten, G., Zool. Bidrag. Upps., 31, 211 (1956); ibid., 32, 67 (1957).

${ }^{5}$ Southward, E. C., and Southward, A. J., J. Mar. Biol. Assoc. UK, 46 579 (1966).

- Norrevang, A., Sarsia, 21, 37 (1965).

${ }^{7}$ Gupta, B. L., Iittle, C., and Philip, A. M., J. Mar. Biol. Assoc. UK, 46, 351 (1966).

${ }^{8}$ Southward, E. C., and Southward, A. J., J. Mar. Biol. Assoc. UK, 37, 627 (1958).

${ }^{9}$ Webb, M., Sarsia, 15, 33 (1964).

io Ivanov, A. V., Zool. Zh., 43, 581 (1964).

${ }^{11}$ Rogers, A. W., Techniques of Autoradiography (Elsevier, Amsterdam, 1967).

${ }^{12}$ Duursma, E. K., in Chemical Oceanography (edit. by Riley, J. P., and Skirrow, G.), 433 (Academic Press, New York, 1965).

13 Degens, E. T., Geochemistry of Sediments (Prentice Hall, New Jersey, 1965).

${ }^{14}$ Chau, Y. K., and Riley, J. P., Deep-Sea Res.,13,1115 (1966).

15 Stephens, G. C., and Virkar, R. A., Biol. Bull. Mar. Biol. Lab. Woods Hole, 131, 172 (1966)

${ }^{16}$ Ferguson, J. C., Biol. Bull. Mar. Biol. Lab. Woods Hole, 132, 161 (1967).

${ }^{17}$ Chapman, G., and Taylor, A. G., Nature, 217, 736 (1968).

${ }^{18}$ Fontaine, A. R., and Chia, F. S., Science (in the press).

\section{Epizootic of Simian Haemorrhagic Fever}

Two epizootics of simian haemorrhagic fever $(\mathrm{SHF})$ have been reported among quarantined Indian rhesus monkeys (Macaca mulatta). The first outbreak occurred in July 1964 at the Sukhumi Institute of Experimental Pathology and Therapy, USSR ${ }^{1,2}$; the second occurred in October 1964 at the US National Institutes of Health (NIH) quar- antine colony ${ }^{3,4}$. The virus causing the NIH epizootic was isolated in cell culture and characterized ${ }^{5}$. Although the Soviet workers showed that the disease could be trans. mitted from monkey to monkey, they have not yet isolated the causative agent in either cell culture or small laboratory animals. This report describes the isolation in cell culture of the virus causing the Sukhumi epizootic and the serological relationship between the viruses causing the Sukhumi and NIH outbreaks.

After isolating the $S H F$ virus strains causing the NIH outbreak we tested sera from monkeys involved in the Sukhumi epizootic by a complement fixation test with a $20 \times$ concentrated virus-infected cell culture antigen prepared from the prototype $L V R \quad 42-0 / M 6941$ strain. Dr Robert J. Huebner kindly supplied us with thirty-six sera given to him by Professor V. D. Soloviev (Moscow) and Professor B. A. Lapin (Sukhumi). None of these sera reacted by complement fixation test. We were not convinced, however, of the lack of relationship because only two monkeys from the NIH epizootic reacted by complement fixation test. When these sera were checked by a more sensitive fluorescent-antibody test (unpublished observations of Tauraso, Aulisio and Shelokov) several reacted in an unfamiliar way with markedly subdued fluorescence. We did not feel that this represented nonspecific reaction because the fluorescence occurred in that part of the cytoplasm and nucleus which we knew contained the viral antigen. It was possible that the reaction represented either a low concentration $\operatorname{IgG}$ antibody or a different class of antibody, possibly the earlier appearing IgM. We knew that low concentrations of complement fixation antibody occurred in some moribund animals when they were also viraemic ${ }^{5}$.

Two of the Sukhumi sera which reacted by fluorescent antibody test were then inoculated intramuscularly into two rhesus monkeys housed in a specially constructed negative-pressure isolator (unpublished observations of Tauraso and Shelokov). One of the animals became ill 2 days after inoculation with a disease indistinguishable from that seen during the NIH epizootic. The second animal became ill 19 days after inoculation and it was not possible to determine whether its illness was caused by inoculation with a very small dose of virus or by exposure to the first sick monkey which was in the same isolator. The pathological findings in both monkeys were similar to those previously described for simian haemorrhagic fever occurring at NIH (ref. 4).

A viral agent which we have called the Sukhumi strain was obtained from each of these two monkeys when they were moribund by isolation in tube cultures of the MA-104 embryonic rhesus monkey kidney cell line using methods previously described ${ }^{5}$. After several passages in cell culture the virus caused typical clinical disease when inoculated into healthy rhesus monkeys and was isolated from the serum of these animals.

The Sukhumi strain was compared with three NIH strains, the prototype $L V R 42-0 / M 6941, L V R 543 / 654$, and $L V R$ 42-0/M6941/BS-C -1. TheSukhumi, $L V R$ 42-0/M6941 and $L V R \quad 543 / 654$ strains produced similar cytopathic effects (CPE) in $M A-104$ cell cultures. The $L V R$ 42.0/ $M 6941 / B S-C-1$ strain having been passaged in $B S-C-1$ cell cultures produced a different CPE in $M A-104$ cells. This was characterized by a more rapid onset, granular appearance and lack of refractile cells characteristic of the CPE produced by the prototype $L V R$ 42-0/M6941 strain ${ }^{5}$.

By fluorescent antibody tagging, specific viral fluorescence was shown both in the nucleus and cytoplasm of cells infected with $S H F$ virus. The four virus strains produced a similar picture. Their serological similarity was shown using the indirect fluorescent antibody technique with coverslips of $M A-104$ cells infected with each of the four strains, serum from a monkey surviving infection with the prototype strain $(L V R 42 \cdot 0 / M 6941)$ as the source of antibody, and fluorescein-conjugated anti-monkey globulin. 